UNIVERSIDAD CATÓLICA DE TEMUCO

\title{
UN CINEASTA CHILENO. KUZMANICH Y EL CINE DE LA VIOLENCIA EN COLOMBIA
}

\author{
Angélica María Mateus Mora ${ }^{1}$
}

Trabajo recepcionado: diciembre 2006

Trabajo aceptado: junio 2007

\section{RESUMEN}

La autora presenta un análisis del film Canaguaro (1981) del chileno Dunav Kuzmanich. Se trata de una realización cinematográfica colombiana profundamente innovadora en su constitución, en cuanto desarrolla una construcción colectiva e imaginaria de la violencia. En este contexto de la violencia sociopolítica de la guerrilla, el protagonista no es necesariamente un personaje, sino que es el pueblo, algo que es interesante pues conecta el cine latinoamericano con una larga reflexión ensayística. Este film, muestra un cine que asume una posición crítica frente a la historia colombiana oficial, con la clara intención de develar episodios ocultos de esta historia, en especial de una etapa particular, donde el cine logra, incluso más que la misma historiografía, representar la complejidad histórica, analizar los procesos internos y proyectar esa realidad histórica al presente.

PALABRAS CLAVE: Kuzmanich, cine colombiano, violencia, imaginario latinoamericano.

\begin{abstract}
The author presents in the piece an analysis about the film Canaguaro (1981) by Chilean filmmaker Dunav Kuzmanich. This was a Colombian production deeply innovative in its constitution due to developing a collective and imaginary construction of violence. In that context of guerrilla socio-political violence, the main protagonist is not a particular character but the people, generating an interesting connection between Latin American filmmaking and long essayistic reflection. This film shows a cinematography that assumes a critical position in the way of an official Colombian history, and with the clear intention of revealing hidden episodes, especially during particular period in which filmmaking was really representing the historical complexity, analyzing internal process and projecting that reality to the present, even more so than historiography.
\end{abstract}

KEYWORDS: Kuzmanich, colombian filmmaking, violence, latin american imaginary.

1 (Universidad de París - 3, doctorado) 
Revista CUHSO volumen 14 n 1

\section{Introducción}

Se ha vuelto un tema común, al hablar del conflicto colombiano actual, decir que este país se encuentra en guerra "desde hace 40 años", o aun "desde hace 50 años", antes del nacimiento de los actuales movimientos de guerrilla. Válida en el sentido de que remite al contexto histórico dentro del cual se inserta la guerra actual, y fuera del cual resulta muy difícil entender la realidad presente de Colombia, esta afirmación puede ser problemática sin con ella se pretende reducir el presente al pasado, borrando las discontinuidades y lo singular de cada momento histórico. Asimismo, puede ser problemática si se pretende justificarla evocando vagamente el hecho de que la guerrilla de las FARC, uno de los actores en el conflicto, es la "guerrilla más antigua del continente americano", con lo cual se sugiere, por lo demás, una interpretación unilateral, simplista e ideológica del conflicto, según la cual en últimas hay conflicto porque hay guerrilla. Para poder afirmar con pertinencia que la sociedad colombiana está en guerra desde hace cuarenta, cincuenta o más años, se requiere entonces identificar las continuidades es esta historia, sin anular las rupturas y discontinuidades. Se requiere mostrar qué relaciones existen entre la guerra actual y el fenómeno de la "violencia" de los años cuarenta y cincuenta. Esta tarea, que pertenece en principio a la historiografía y a las otras ciencias humanas, pero que no puede ser separada al mismo tiempo de la construcción social de memoria, ha sido asumida parcial y fragmentaria por la creación cinematográfica colombiana. A ella contribuyó, en los propios orígenes del cine colombiano de la violencia, una película realizada a finales de la década del setenta por un cineasta chileno radicado en Colombia desde 1973: Canaguaro (1981), de Dunav Kuzmanich Salinas.

\section{El proyecto de Canaguaro}

Dunav Kuzmanich emprende la realización de Canaguaro en 1978, cinco años después de su llegada a Colombia, en 1973. Como muchos otros chilenos, Kuzmanich había tenido que abandonar su país a raíz del golpe militar del 11 de septiembre de aquel año. Al llegar a Colombia, ya tenía una cierta experiencia cinematográfica: nacido en Chile en 1935, hijo de un inmigrante yugoslavo, Kuzmanich había trabaj ado en Argentina como guionista y, entre 1967 y 1971, había dirigido en su país el noticiero de televisión Chile en Marcha, y realizado varios documentales²; asimismo, había sido profesor de producción de cine en la Escuela de Artes de la Comunicación de la Universidad Católica de Chile, entre 1970 y 1972.

En Colombia, Kuzmanich reencuentra a los hermanos Pepe e Israel Sánchez, dos colombianos que había conocido en 1967 en Santiago. Con ellos surge la idea de realizar una película de carácter histórico y político, sobre el periodo Ilamado de "Violencia". Con este término genérico de Violencia (con mayúscula) se designa habitualmente un fenómeno mayor de la historia colombiana del siglo veinte, que encuentra su máxima expresión en el periodo comprendido entre 1948 y 1958. Dentro del contexto histórico colombiano, la violencia designa una forma inédita de violencia, distinta a la que conoció el país durante las guerras civiles del siglo diecinueve, en las que se enfrentaban generalmente los liberales a los conservadores. La violencia no fue una guerra civil en el sentido estricto, pero provocó más víctimas y destrucciones que todos los conflictos armados del siglo precedente. Vinculada, en buena parte, al antagonismo político tradicional entre el liberalismo y el conservatismo, la violencia introduce nuevos actores, nuevos intereses, nuevas formas de violencia. También se inserta dentro del conflicto cultural entre la "modernidad" y la "tradición", determinando profundas transformaciones en la cultura, particularmente en la cultura moral, política y religiosa de la sociedad colombiana. La violencia constituye un verdadero cambio en la historia colombiana del siglo veinte. Sus efectos se prolongan en la violencia que marca la historia contemporánea de este país.

Kuzmanich y sus asistentes colombianos optan por abordar el tema de la violencia no desde su dimensión política partidista (el conflicto tradicional entre liberales y conservadores, que se reactiva violentamente en el siglo XX a partir de 1930) sino desde su aspecto político social, que encuentra una expresión particularmente significativa entre 1949 y 1953, con la aparición y desarrollo de una fuerte movilización armada de campesinos "liberales" en la región de Los Llanos orientales. La insurrección de Ios Llanos abre una nueva fase de la violencia, marcada

2 Entre ellos se cuentan los mediometrajes J uan maula (1966) y Desafío (1967), así como el documental de largometraje Cuando Amanece. 
esencialmente por la transformación progresiva del tradicional conflicto liberal-conservador en conflicto social, oponiendo el "pueblo" (campesinos pobres armados) a "la oligarquía" (los grandes propietarios y la clase política tradicional). Esta opción "social" de la película es explicitada por Kuzmanich en una entrevista acordada en 1981 a la revista Cine, con motivo del estreno de Canaguaro:"Queríamos hacer una película esencialmente colombiana (...) y tratar de calar en algún aspecto básico de la nacionalidad a través de su historia" ${ }^{3}$. En su concepción inicial, el proyecto se relacionaba de este modo con la cuestión general de las relaciones entre la historia y la "identidad". En Colombia, pensaban Kuzmanich y sus colaboradores, la historia de las violencias ejercidas contra la población campesina socialmente desfavorecida es un elemento característico de la historia del país, y, en ese sentido, un contenido que participa en la definición de la identidad colombiana. Por otra parte, Kuzmanich establece un vínculo entre la Violencia, como fenómeno histórico, y la "épica", como género narrativo y cinematográfico particular. Como los poemas épicos de la tradición escrita u oral, el "cine épico" busca transmitir una memoria común de conflictos, valorizando los hechos y las gestas de una comunidad frente a otras comunidades, y contribuyendo así a la construcción de una identidad propia. El western norteamericano ${ }^{4}$, el cine derivado de las revoluciones rusa y mexicana, las películas sobre los cangaceiros en el cine brasileño y sobre los samuráis en el cine japonés, serían, según Kuzmanich, formas del "cine épico" que contribuyen al nacimiento y mantenimiento de un sentimiento de identidad 5 . En esta perspectiva, la opción por el tema de Canaguaro se justifica por la idea según la cual la representación épica de la historia, valiéndose del cine "épico", aporta una contribución fundamental a la reflexión de un público que, partiendo de esa representación, será llevado a reflexionar sobre su identidad: "¿Quiénes somos?", "¿de dónde venimos?" (...) Creo, pues, que este tipo de respuesta es más fácil empezar a darla a partir de este tipo de cine, el épico, y de ahí que eligiéramos el tema de la violencia" 6 . En Kuzmanich, la intención de abordar un aspecto particularmente significativo de la identidad nacional a través de la representación de un momento de su historia es correlativo con la voluntad de "hacer un filme esencialmente colombiano. Prescindir del lugar común, de la aproximación superficial o pintoresca, o meramente costumbrista" ${ }^{7}$. Desde este punto de vista, Canaguaro se vincula al nuevo cine colombiano de ficción que surge a partir de los años sesenta: después de tres décadas de crisis estructural, este cine proponía una mirada cinematográfica inédita sobre las realidades del país, inspirándose en parte del neorrealismo italiano (Raíces de Piedra, de José María Arzuaga, 1962; El Río de las Tumbas, de Julio Luzardo, 1964). Realizado entre 1978 y 1980, Canaguaro representa un acontecimiento en la historia del cine colombiano: por primera vez es realizado, fuera de la producción fílmica destinada a la televisión, un largometraje de ficción que se propone explícitamente representar de manera relativamente sistemática un momento de la historia del país ${ }^{8}$.

\section{La realización del filme}

\section{a) El Guión}

La elaboración del guión de este primer filme sobre la historia de la Violencia en Los Llanos conoció tres etapas. Inicialmente, Kuzmanich y su equipo conciben la idea de un guión basado en la historia de Guadalupe Salcedo, el jefe más célebre de las guerrillas de El Llano, asesinado en 1957. Sin embargo, en 1978, la historia de Guadalupe Salcedo no había sido hecha, como, de alguna manera, no lo es todavía. El equipo de cineastas debe entonces comenzar un trabajo de investigación histórica, que trata esencialmente sobre

3 KUZMANICH, D., "Canaguaro. Historia de peripecias" (entrevista colectiva), en: Cine, No 4 (junio-julio 1981), p .1.

4 En un sentido cercano al evocado por Kuzmanich, Michel Serceau ha hablado de un "western épico". Ver: Michel SERCEAU, Étudier le cinéma, Editions du temps, París, 2001, p. 129. Este género ha sido calificado en varios ciclos: ciclo del "asentamiento" o de la invasión, ciclo de guerras indígenas, ciclo de la guerra contra México, etc. Ver: J ean-Louis RIEUPEYROUT, Le Western ou le cinéma americain par excellence. Cerf, Collection "7è Art", París, 1953; La Grande aventure du westrn. Du Far-West à Hollywood: 1894-1963, París, Ramsay, 1987. El conjunto de esta producción manifiesta la presencia, en el cine de Hollywood, a partir de 1910, de un proyecto de constitución simbólica e ideológica de la "nación america". Ver: Raphaëlle MOINE, Les genres du cinéma, Nathan, París, 2002, pp. 25-26

5 El empleo que hace Kuzmanich de la relación entre el género épico y la cuestión de la identidad parece problemática, en la medida en que confunde identidad social e identidad cultural. Kuzmanich emplea el término "épico" en un sentido muy amplio y poco riguroso, designando finalmente toda suerte de narraciones de hechos y gestas de un grupo dado.

6 Ibid.

7 KUZMANICH, D, texto citado, p. 1.

8 En 1915, los hermanos Acevedo habían realizado el cortometraje El drama del 15 de octubre, cuyo tema es el asesinato del dirigente liberal Rafael Uribe, en 1914. 
Revista CUHSO volumen $14 \mathrm{n} \div 1$

dos tipos de fuentes: escritas (narraciones, crónicas y, sobre todo, el libro de Eduardo Franco Isaza Las Guerrillas del Llano, publicado en 1959) y orales (entrevistas a testigos, refugiados o protagonistas de la guerrilla de Los Llanos) ${ }^{9}$. Sin embargo, en el transcurso de esta investigación, los cineastas tropiezan con la dificultad de separar el personaje histórico del personaje mítico: "el trabajo era muy difícil, sobre todo porque Guadalupe estaba convirtiéndose en un mito"; frecuentemente los testimonios no coincidían y los hechos eran "idealizados"10. El grupo decide, entonces, abandonar este proyecto inicial de guión, y proyectan abordar de manera más general la historia de la Violencia en Los Llanos.

La tarea de escritura de este segundo guión es confiada al dramaturgo Sergio Vodanovic. En ocho meses de trabajo, Vodanovic elabora una narración que, cubriendo varios años, integra una multiplicidad de personajes y de hechos. Ahora bien, este nuevo guión -el primero escrito- implica un presupuesto que superaba las posibilidades del grupo. Por otra parte, el guión de Vodanovic fue objeto de una doble crítica por parte de Kuzmanich: a nivel de forma, el realizador lo juzgaba "un poco convencional", y a nivel del contenido, lo consideraba demasiado orientado hacia los personajes, lo cual permitía reconstruir lo que sería según él la realidad del fenómeno que se trataba de representar. Había que tratar el tema como "un hecho de grupos en conflicto" ${ }^{11}$. Es a partir de este criterio que un segundo guión escrito se elabora.

El tema de este último guión es propuesto por Pepe Sánchez, a partir de una de las secuencias del texto preparado por Vodanovic: el episodio que cuenta el periplo de un grupo de guerrilleros en Los Llanos, en búsqueda de las armas prometidas por la dirección del Partido Liberal. A partir de la narración de este periplo, tomado como hilo principal, Kuzmanich y sus asistentesguionistas (Pepe Sánchez e Isabel Sánchez) elaboran otras tres narraciones, contadas por tres personajes: Antonio, Canaguaro ${ }^{12}$ y Gabriela, todos ellos miembros del grupo de guerrilleros que buscan las armas prometidas. Estas tres narraciones biográficas son testimonios personales de la violencia: Antonio es testigo de la destrucción de su pueblo por las hordas de los conservadores, y ha visto su familia masacrada y su hermana violada por los policías chuladitas ${ }^{13}$; Gabriela ha sido violada por un militar o policía chuladita, y, convertida en prostituta, se vengará más tarde de su agresor. Integrando a la narración principal estas tres narraciones biográficas, los guionistas esperaban mostrar la génesis de la Violencia y la "Iucha campesina en Los Llanos" ${ }^{14}$. En la perspectiva propuesta por el argumento definitivo del filme, la formación de los grupos de guerrilla en Los Llanos aparece como una respuesta social a la violencia del poder conservador, violencia que es perpetrada a través del ejército y de la policía, la cual es identificada en el filme como las bandas de asesinos conservadores designados bajo el nombre de "chuladitas".

A partir de este argumento definitivo, construido sobre la base de fuentes escritas y de testimonios de los refugiados de la Violencia instalados en Bogotá, el grupo de cineastas elabora el guión definitivo durante el rodaje, siguiendo un método original. Antes del rodaje de cada secuencia, el conjunto del grupo (realizador, guionista, actores y técnicos) se reúne para determinar, a partir de situacionestipo y de personajes-tipo definidos por el argumento general, los elementos particulares de la narración y de la puesta en escena de la secuencia ${ }^{15}$. Los elementos particulares de los diálogos y de la dramaturgia son elaborados esencialmente por los propios actores, de acuerdo con el realizador. Una parte de la música de la película -canciones y coplas del cantante Ilanero Arnulfo Briceño- es compuesta igualmente durante el rodaje, a partir de las situaciones construidas para la narración ${ }^{16}$. Dejando un largo espacio para la improvisación

9 KUZMANICH, D, entrevista citada, p. 2. Ver también: Isabel SÁNCHEZ MÉNDEZ (compiladora), El cine de la violencia, Ediciones de la Universidad Nacional de Colombia, 1987, p. 19.

10 KUZMANICH, D, ibid.

11 Ibid. pp. 2 y 3.

12 En la región de los Llanos, se Ilama “canaguaro" a una variedad de tigrillo. El héroe del filme, un guerrillero campesino, lleva en su nombre los atributos del tigrillo (agilidad, fuerza, valor).

13 El término "chuladita", proviene del nombre de una vereda del pueblo de Boavita en el departamento de Boyacá, designa un asesino ligado al Partido Conservador, que puede ser policía, militar o civil. Empleado exclusivamente por los liberales o, de manera más general, por los no conservadores; El término puede designar también, por extensión, cualquier miembro del Partido Conservador

14 Pepe SÁNCHEZ (entrevista), en: "Canaguaro, historia de peripecias", Cine, número citado, p. 2.

15 "Se puede decir que todos los diálogos son improvisados por los actores a partir de dos hechos: una situación dada y el personaje que se encontraba en esa situación". D. KUZMANICH, Ibíd., p. 4.

16 Arnulfo BRICENO (entrevista) en Cine, número citado, pp. 10-11. 
y para la participación de todos, la creación del guión se continúa durante todo el rodaje. De este modo, el texto definitivo del guión es establecido por Sara Libis, la script, después de la realización del filme.

Sinopsis: En 1953, en el momento en que la guerrilla campesina de Los Llanos amenaza con escapar del control del partido liberal, el comandante guerrillero Santos confía a "Canaguaro", guerrillero cuya familia fue masacrada por loschuladitas (policía partidaria, bajo el control de los conservadores), la misión de ir, con un pequeño grupo de hombres, a buscar un importante suministro de armas prometidas por la dirección del partido. Vargas, el representante enviado de Bogotá, propone a los hermanos Lesina, dos ricos hacendados liberales, de reunirse con el grupo de guerrilleros y asumir la dirección política de la misión. A pesar de su oposición a la operación y su hostilidad a los campesinos guerrilleros, los Lesina deciden acompañar al grupo. Después de una larga marcha, en el transcurso de la cual Canaguaro y los otros guerrilleros rememoran las atrocidades cometidas contra ellos o contra sus familias por los chuladitas, el grupo llega al lugar convenido para recibir las armas. Entre tanto, el general Gustavo Rojas Pinilla Ilega al poder por medio de un golpe de Estado. En lugar de entregarles las armas prometidas, el representante del Partido Liberal exhorta a los guerrilleros a deponer las armas. La mayoría acepta, confiando en la promesa de amnistía. Al poco tiempo, son asesinados. Una minoría opta por continuar la lucha.

\section{b) Producción y Rodaje}

La realización de la película tiene lugar en un momento que corresponde a un cambio importante en la historia del cine en Colombia, marcado por el nacimiento de FOCINE (Compañía de Fomento Cinematográfico). Creado por el Estado colombiano, en 1978, con el objetivo de promover el desarrollo del cine nacional, esta institución permitió estimular la creación cinematográfica del país, durante la década del ochenta y hasta su desaparición oficial en 1992. El proyecto de Canaguaro precedió el nacimiento de FOCINE, y su rodaje se hizo antes de que la institución comenzara a funcionar efectivamente, a partir de los últimos meses de 1979. El primer financiamiento del filme es asegurado por medio de préstamos acordados por FONADE (Fondo Nacional de Desarrollo), por el Banco Corporación Financiera Popular, y por otros aportes personales. El actor Alberto J iménez crea la sociedad Producciones Alberto J iménez, que negocia el préstamo con FONADE. Para la última fase de la realización, los cineastas obtienen un aporte de FOCINE. De manera general, el grupo dispone de pocos recursos, y las dificultades de financiamiento retardaron considerablemente la finalización de la obra.

El rodaje de la película comienza en 1978, y dura dos meses. A causa de las limitaciones financieras no se efectúa en Los Llanos, sino en el valle del río Magdalena, en Méndez, cerca de la ciudad de Honda. Las condiciones de vida y de trabajo son difíciles: en el lugar apartado, donde se instala el grupo, compuesto de unas treinta personas, había frecuentes problemas de aprovisionamiento. El grupo recibe ayuda de los habitantes de la región, que colaboran además en la fabricación de elementos del decorado y aceptan participar como extras. El ejército suministra algún material (colchonetas, armas y municiones inofensivas). En razón de las dificultades financieras, los cineastas deben inventar ciertas soluciones técnicas (sonido en directo, iluminación a partir de sistemas de reflexión de la luz natural, rodaje en 16 $\mathrm{mm}$ y luego copia en $35 \mathrm{~mm}$ ), y retardar varios meses la fase final. Estas deficiencias técnicas afectan la calidad estética de la obra.

El grupo cuenta con catorce actores, la mayoría profesionales y semiprofesionales provenientes del teatro. Pepe Sánchez (el "doctor Vargas"), el asistente principal de Kuzmanich, era actor de televisión; había comenzado su formación cinematográfica hacia mediados de los años 60. Después de la realización de un primer cortometraje sobre la vida de un gamín ${ }^{17}$ de Bogotá ("Chichigua"), fue a Chile en 1966, donde se reúne con su hermana María Isabel Sánchez y conoce a Dunav Kuzmanich. Durante su estadía en Chile, que se prolonga hasta 1973, trabaja como asistente en la realización de varias películas. A su regreso a Colombia, realiza el cortometraje $\mathrm{El}$ patas (1978), con la colaboración de Kuzmanich como asistente de dirección y coguionista, justo antes de la elaboración del proyecto Canaguaro. Marcelo Romo ("Manuel Lesina") había actuado en El Chacal de Nahueltoro, el

17 Término con el que se designa en Colombia a los niños abandonados, que viven en la calle. 
célebre filme del cineasta chileno Miguel Littin (1970). Álvaro Ruiz (el sargento responsable de la masacre de la familia de "Canaguaro") era un actor conocido de la televisión colombiana, y había tenido una experiencia en el ejército; en el momento de la creación de Canaguaro, interpretaba el rol de Simón Bolívar en el filme histórico Manuelita Sáenz, realizado para la televisión. Hernando Casanova ("el profe"), era igualmente actor de televisión (serie Yo y tú, de 1958 a 1974), y había actuado en El Patas, de Pepe Sánchez; antes de sus inicios en el cine, había sido parte de la infantería de marina y del ejército, y también trabajó como profesor. Alcira Rodríguez ("Gabriela"), Alberto J iménez ("Canaguaro"), Eva Bravo (la hermana de Canaguaro) y otros más, tenían una experiencia como actores de cortometrajes 0 de teatro.

\section{c) Recepción de la Película}

Canaguaro se estrena en 1981. Dentro del marco del circuito comercial, es presentada únicamente en Bogotá en el teatro Colombia, hoy cine J orge Eliecer Gaitán. El público Ilena esta gran sala durante al gunas semanas ${ }^{18}$, hasta el momento en que la dirección del teatro Colombia decide de manera imprevista detener la proyección del filme. Según Oswaldo Osorio, el retiro de la película del circuito comercial obedecería a presiones políticas externas ${ }^{19}$. Isabel Sánchez, la asistente de Kuzmanich, sugiere igualmente que el filme pudo ser objeto de una forma no oficial de censura ${ }^{20}$. A pesar de estas dificultades, Canaguaro obtiene dos menciones, en los festivales de Cartagena y de La Habana, así como el premio de la UNESCO y de la ciudad de Nantes en el festival Trois Continents, en 1982. Posteriormente, un contencioso jurídico con una de las instituciones que facilitaron un crédito para la realización, tuvo como consecuencia la prohibición de su explotación comercial ${ }^{21}$.
De manera general, el filme fue bien recibido por la crítica, que ve en Canaguaro la emergencia de un nuevo cine en Colombia. El suplemento cultural del diario El Espectador subraya la importancia del filme para una apropiación crítica de la historia: Canaguaro nos enseña que "nosotros (Ios colombianos) somos capaces de mirar nuestro pasado" ${ }^{22}$. En la misma perspectiva, otro crítico anota que "el valor del filme reside en su lectura política de nuestra historia": una lectura que "no teme ir a lo más profundo de esta historia", a contracorriente de la "historia oficial" que calla los hechos de la "...violencia", (de) la guerrilla liberal y de la ulterior traición (de la cual fue víctima esta última)" ${ }^{23}$. Un año más tarde, el historiador de cine Hernando Martínez Pardo incluye a Canaguaro entre los cuatro filmes que entre 1974 y 1982 marcaron "el resultado de búsqueda cinematográficas" del periodo anterior ${ }^{24}$. Martínez Ilama la atención sobre la novedad que encarnan estos cuatro filmes, que proponen, cada uno a su manera, una relectura de la "historia oficial". Respondiendo a la "necesidad humana de situarse en la historia" y asumiendo "el rol que el arte ha jugado siempre como medio de investigación", este cine se vincula también al "presente en crisis", cuya comprensión reclama una relectura del pasado: películas como Canaguaro contribuyen a aclarar los "orígenes del presente" 25. Esta misma idea es retomada tres años después por el crítico J orge Ayala Blanco, con motivo de la proyección del filme en el marco de la Semana del Filme Colombiano en la cinemateca de Bogotá: Canaguaro -dice Ayala- propone una "revisión polémica" y una reflexión "necesaria y dolorosa" sobre la historia del país, que acerca el filme del "mejor cine histórico de America Latina, el de Toboada y Sanjinés" ${ }^{26}$. El interés histórico del filme es subrayado igualmente por la revista especializada Ercadia va al cine, que, en un informe sobre el tema "violencia política y cine en Colombia",

18 Una decena de días, según Isabel Sánchez Méndez, o tres semanas según Oswaldo Osorio. Ver: SÁNCHEZ, I, “Sobre la película Canaguaro" (entrevista con Angélica Mateus Mora, 31 marzo 2004); OSORIO, O, "En busca del cuarto cine", en Kinetoscopio, № 58 (2001), p. 24. Este número de la revista presenta un informe especial sobre el "cine político". El artículo de Osorio ha sido retomado en Cuadernos de Cine Colombiano, Balance argumental, Cinemateca Distrital, Bogotá, 2002, con el título: "A lo políticamente correcto".

19 Oswaldo OSORIO, ibid.

20 "El teatro dijo que tenía otros compromisos, (y) mucha gente nos evita...". Respuesta de Isabel Sánchez a nuestro cuestionario (31 de marzo 2004). Archivos personales.

21 Posteriormente, Kuzmanich realizará otras creaciones en Colombia: La agonía del difunto (1981), Ajuste de Cuentas (1983), El día de las Mercedes (1985) y Mariposas (1986).

22 LEÓN, A, “El aplauso, el mejor premio", en Magazín Dominical, El espectador, 5 de julio 1981.

23 Octavio ARBELAEZ TOBON, "Canaguaro", en Fabularia. Fecha aproximada de publicación 1981.

24 Hernando MARTínEZ PARDO, "Panorámica del cine colombiano 1958-1982", en Cine, № 9 (julio- agosto 1982), pp. 8-9. Los otros tres filmes son Camilo, el cura guerrillero (Francisco Norden, 1974), Gamín (Ciro Durán, 1979) y Nuestra voz de tierra, memoria y futuro (J orge Silva y Marta Rodríguez, 1982).

25 Hernando MARTÍNEZ PARDO, ibid.

26 J orge AYALA BLANCO, "Godos contra cachiporras en berracas canciones de gesta", en la sección "Cine Colombiano" de un periódico del cual no disponemos sino fragmentos. Fecha probable de publicación: 1985. 
considera que Canaguaro hace parte de la producción cinematográfica colombiana que es movida por una "búsqueda insaciable de la memoria histórica y política" ${ }^{27}$. Ahora bien, si las críticas concuerdan en general sobre el valor de su contenido histórico, su juicio es menos consensual en lo que se refiere a su valor cinematográfico: algunos lo consideran como el filme "más logrado del cine político en Colombia" 28; mientras que otros, que ponen en relieve sus insuficiencias técnicas y narrativas, consideran que la película no suministraba una respuesta "a las necesidades del cine nacional" 29.

\section{El aporte de Canaguaro}

Canaguaro es, junto con la película de Fernando Vallejo, En la tormenta (1981), una de las dos películas colombianas que abordan de manera suficientemente explícita y directa el tema de la Violencia, que desde dos décadas atrás ocupaba un lugar central en la pintura y la creación literaria de Colombia, particularmente después de la segunda mitad de los años cincuenta. Estas dos películas inauguran un cine de la Violencia, que en los años siguientes producirá varios largometrajes, marcando una renovación del cine colombiano después de un largo periodo de crisis: Carne de tu carne (Carlos Mayolo, 1983), Cóndores no entierran todos los días (Francisco Norden, 1984), Caín (Gustavo Nieto, 1984), El potro chusmero (Luis Alberto Sánchez, 1985) y Confesión a Laura (J aime Osorio, 1988).

De todas estas películas, Canaguaro es la única que propone una reconstitución histórica general de la Violencia. La película sitúa los hechos relativos a la guerrilla "liberal" de Los Llanos en un contexto histórico más amplio, definido por el asesino del líder popular J orge Eliecer Gaitán (1948) y las persecuciones llevadas a cabo por el poder conservador hasta 1953. En tanto que filme histórico, Canguaro busca proponer claves para comprender la historia de la violencia: identifica una serie de hechos históricos, los reúne al interior de una narración y les confiere así un sentido. En la representación que el filme propone del periodo 1948-1953, insiste sobre las determinaciones sociales del conflicto y subraya las ambigüedades de la política del Partido Liberal de la época, política que comporta numerosas zonas obscuras que no han sido aún elucidadas, particularmente en lo que concierne a las relaciones entre la dirección del partido y los movimientos rurales de autodefensa liberal. De esta manera, representando informaciones silenciadas por la "historia oficial", Canaguaro hace parte de las películas que, según Marc Ferro, contribuyen a la elaboración de la Historia como ciencia o como discurso ${ }^{30}$. Este aporte a una apropiación histórica de la tragedia de la Violencia hubiera podido sin duda ser mayor, si la película no hubiese incurrido en una serie de simplificaciones: las bandas de chuladitas son pura y simplemente asimiladas al ejército y a la policía, con lo cual se oculta la dimensión propiamente civil del conflicto entre "liberales" y "conservadores", en sus aspectos ideológicos, político-ideológico, la película presenta al "pueblo" como tal, y no a la población liberal, como víctima de las persecuciones del Gobierno conservador, Io cual históricamente es sin duda problemático.

Sin embargo, el interés histórico de Canaguaro no se reduce a su significación del filme histórico solamente. En efecto, Canaguaro es, al mismo tiempo, un filme que busca reconstruir en el presente una memoria social y política. La historia representada de manera épica en la película es la historia del "pueblo" en armas. Los héroes de la película son los hombres y las mujeres de origen social modesto o desfavorecido (campesinos, pequeños propietarios, aparceros o maestros de escuela) que han sufrido la opresión de un ejército y de una policía que mata, viola y roba, y han tomado la opción de defenderse con las armas, antes de ser finalmente traicionados por los hacendados liberales y por Ia dirección del Partido Liberal. El verdadero héroe del filme es, finalmente, el "pueblo", y el heroísmo de las personas deriva en últimas de su pertenencia a ese "pueblo" que sufre, resiste y soporta la traición. La toma de conciencia que la película busca suscitar es entonces una toma de conciencia social, y los contenidos simbólicos que señala se vinculan a la lucha de los más desfavorecidos por la justicia social y a la afirmación del "pueblo"

27 "Violencia política y cine en Colombia", en Arcadia va al cine, año VI, № 18 (junio-julio 1988), pp. 34-35 (sin indicaciones sobre el autor).

28 Ver Oswaldo OSORIO, artículo citado, p. 22.

29 Luis Alberto ALVAREZ, “El cine en la última década del siglo XIX. Imágenes colombianas”, en J orge Orlando MELO (ed.), CoIombia hoy. Perspectivas hacia el siglo XXI, Ediciones Tercer Mundo, Bogotá, 1995 (XV ediciones revista y corregida), p. 363. Primera edición: 1978.

30 Marc FERRO, Cinéma et histoire, Gallimard, collection “Folio", París, 1992, pp.12-20. 
como sujeto de la historia y como base de la identidad nacional. La obra de Kuzmanich proyecta aquí ser el agente de una historia de la emancipación del "pueblo", y, de este modo, se dirige esencialmente a un público "popular". Así, la lectura del fenómeno de la violencia en general y de la guerrilla de Los Llanos en particular, propuesta por Kuzmanich a través de Canaguaro, se basa en una finalidad política que busca despertar la conciencia de la autonomía del "pueblo", liberarlo de las mistificaciones de la política liberal tradicional, conducirlo hacia una acción emancipadora en el presente, es decir, los últimos años de la década de los setenta y el comienzo de la época de los ochenta. A través del filme, los cineastas se proponen actuar en el presente, concediendo así a su actividad cinematográfica el significado de "agente de una toma de conciencia social o cultural" ${ }^{31}$, según la expresión de Marc Ferro.

Por eso, al lado del referente histórico explícito (la Violencia de 1948-1953), la película comporta un segundo referente histórico, implícito: el presente de 1978- 1980. Diversos elementos narrativos señalan que el referente presente modela la representación del pasado, en particular en lo que concierne la manera de representar las relaciones entre la guerrilla de Los Llanos y el Partido Liberal, Ia marcha por las armas, la emergencia de una nueva guerrilla y su composición social, así como también en lo que se refiere a la manera de no representar la dimensión propiamente política e ideológica del conflicto entre "liberales" y "conservadores". Resulta significativo que el propio público de la película haya podido desplazar el referente explícito hacia otros periodos, posteriores a la época de su realización: hacia 1986, en el momento de la desmovilización de la guerrilla del M-19, un texto publicado en la prensa se refiere a Canaguaro para evocar la perspectiva de una posible repetición del destino trágico de Ios guerrilleros de Los Llanos que depusieron sus armas en 195332; en 1999, no muy lejos de nuestro presente, el crítico e historiador del cine, Mauricio Laurens, retoma el mismo paralelo, a propósito de los proyectos de amnistía para los guerrilleros de la nueva guerrilla que acepten deponer sus armas ${ }^{33}$.

Realizado en un contexto marcado por el desarrollo de la nueva guerrilla histórica (FARC, ELN, EPL, M-19 y otros grupos menores), el filme representa los elementos de comunidad y de ruptura entre la antigua guerrilla "liberal" y la nueva guerrilla que surge del rechazo de una capitulación sin verdadera contraparte. Los elementos de continuidad (origen de los combatientes, permanencia de una situación de exclusión social, control de la política por parte de los ricos hacendados) confieren a la nueva guerrilla una forma de "legitimidad" histórica, por medio de la transferencia de la condición de la autodefensa campesina contra los chuladitas a la condición de los grupos que propenden la transformación revolucionaria de la sociedad. Los elementos de ruptura (paso de la dependencia frente al Partido Liberal a la autonomía, y del referente ideológico de revolución social) aparecen como una respuesta histórica del "pueblo" a los acuerdos del Partido Liberal con los ricos hacendados, y, más particularmente, al no respeto de la amnistía por parte del régimen, y al asesinato de los dirigentes guerrilleros desmovilizados. De este punto de vista, y como lo indica tanto las referencias más recientes a la película como la historia de la desmovilización de ciertos grupos de guerrilla o la historia del partido de oposición Unión Patriótica ${ }^{34}$, la película Canaguaro sigue planteando, hoy todavía, la cuestión de las condiciones de una verdadera política de paz en Colombia, capaz de conducir a una superación duradera de la situación de violencia.

31 Marc FERRO, Cinéma et histoire, Gallamard, Collection "Folio", París, 1993, p. 19

32 “Canaguaro es (...) el cantar de gesta de la traición inminente y de las esperanzas desechas (...). ¿Nadie habrá de aprender esa lección?, ¿se repetirá la historia colombiana en la actual desmovilización del M-19 por Betancourt?". Jorge AYALA BLANCO, “Godos contra cachiporras en berracas canciones de gesta" (documento sin referencias bibliográficas).

33 "Comandante de una guerrilla liberal que surgía en aquel entonces como recurso desesperado de la resistencia, Guadalupe Salcedo se halla indisolublemente ligado con tal espíritu de lucha. Esta cinta (Canaguaro), filmada hace casi veinte años, trasciende sobre la realidad política nacional para plantear las maniobras en torno a una amnistía de los grupos alzados en armas". LAURENS, Mauricio, "La violencia política y social en la historia del cine colombiano", en: OSSA, Germán (ed.). Nido de Cóndores. Memoria del IV Encuentro, Editorial Papiro, Pereira, 1999, p. 57.

34 Entre 1986 y 1990 más de un millar de miembros de este partido político de izquierda fueron asesinados en el país, entre ellos dos candidatos presidenciales, tres senadores, tres representantes a la cámara, seis diputados, 89 consejeros municipales y nueve alcaldes. Ver: MUNERA RUIZ, Leopoldo, Rupturas y continuidades. Poder y movimiento popular en Colombia 1968-1988, Lepri- Cerec, Bogotá, 1988, p. 434; J IMÉNEZ, Absalón, Democracia en tiempos de crisis 1949- 1994, Lepri, Bogotá, 2003, pp.172-175. 